\title{
Correction: PIAS1 and TIF1y collaborate to promote SnoN SUMOylation and suppression of epithelial-mesenchymal transition
}

\author{
Ayan Chanda - Yoshiho Ikeuchi - Kunal Karve - Anusi Sarkar • Amrita Singh Chandhoke - Lili Deng • \\ Azad Bonni $(\mathbb{D} \cdot$ Shirin Bonni
}

Published online: 18 August 2020

(c) The Author(s), under exclusive licence to ADMC Associazione Differenziamento e Morte Cellulare 2020

Correction to: Cell Death \& Differentiation https://doi.org/10.1038/s41418-020-0599-8

The original version of this article omitted the following from the "Acknowledgements":

We would like to thank Dr. Derrick Rancourt and Dr. Tannin Schmidt for use of the Olympus IX70 and the Olympus Fluoview FV1000 fluorescence microscopes, respectively. This work was supported by grants from the Natural Sciences and Engineering Research Council of Canada (NSERC), the Canadian Cancer Society (CCS), the Breast Cancer Society of Canada (BCSC) and the Calgary Centre for Cancer Research (CCCR) to S. Bonni, and the
National Institutes of Health (NIH)-NS041021 to A. Bonni. A. Chanda is a recipient of a Charbonneau Cancer Institute Director's Award for Excellence in Research Productivity, an Eyes High International Doctoral Scholarship, a William H Davies Medical Research Scholarship, an Achievers in Medical Science (AIMS) Graduate Recruitment Scholarship, and an Eyes High Recruitment Award from the University of Calgary. K. Karve and A. Sarkar are recipients of a Doctoral Scholarship and an Eyes High Doctoral Recruitment Scholarship, respectively, from the University of Calgary.

This has now been corrected in both the PDF and HTML versions of the article. 